\title{
SÍNTESE DE NANOCATALISADORES A BASE DE Au/C, Pd/C E AuPd/C. INVESTIGAÇÃO ESPECTRO-ELETROQUÍMICA DA OXIDAÇÃO DE ETANOL EM MEIO ALCALINO
}

\author{
L. S. R. Silva ${ }^{1}$, C. T. Meneses ${ }^{2}$, E. A. Batista ${ }^{3}$, K. I. B. Eguiluz ${ }^{1}$, G. R. Salazar-Banda ${ }^{1}$ \\ ${ }^{1}$ Laboratório de Eletroquímica e Nanotecnologia, Instituto de Tecnologia e Pesquisa / \\ Programa de Pós-graduação em Engenharia de Processos, Universidade Tiradentes \\ ${ }^{2}$ Universidade Federal de Sergipe, Departamento de Física \\ ${ }^{3}$ Universidade Estadual Paulista, Departamento de Físico-Química
}

lays.reis@yahoo.com.br

\begin{abstract}
RESUMO - Neste trabalho foram desenvolvidas nanopartículas bimetálicas do tipo liga e casca-núcleo de $\mathrm{Pd}$ e/ou $\mathrm{Au}\left(\mathrm{Pd}_{1-x}-\mathrm{Au}_{\mathrm{x}} \mathrm{C}\right.$, onde $x=0,25 ; 0,33 ; 0,66$; $0,75)$, pela redução sequencial dos precursores $\mathrm{PdCl}_{2}$ e $\mathrm{HAuCl}_{4} \cdot 3 \mathrm{H}_{2} \mathrm{O}$. A atividade catalítica dos catalisadores frente à oxidação de etanol foi estudada por voltametria cíclica e por espectroscopia no infravermelho com transformada de Fourier in situ, enfatizando a determinação quantitativa de intermediários e produtos envolvidos na reação de oxidação. Os espectros mostraram que para a estrutura casca-núcleo a maior parte do etanol não foi completamente oxidada a acetato. A partir da integração da banda de $\mathrm{CO}_{2} \mathrm{em} 2343 \mathrm{~cm}^{-1}$ a seletividade para a oxidação de etanol a $\mathrm{CO}_{2}$ (existente como $\mathrm{CO}_{3}{ }^{2-}$ em meio alcalino) do catalisador casca-núcleo $\left(\mathrm{Pd}_{0,75} @ \mathrm{Au}_{0,25} / \mathrm{C}\right)$ de área igual a $14,502 \mathrm{~cm}^{-1}$ foi $77,8 \%$ superior ao catalisador liga $\mathrm{Pd}_{0,75} \mathrm{Au}_{0,25} / \mathrm{C}$ com área de $1,738 \mathrm{~cm}^{-1}$. Imagens de MET revelaram que a superfície das nanopartículas é constituída por $\mathrm{Pd}$, revelando que o $\mathrm{Au}$ foi encapsulado. Estes resultados concordam com testes iniciais de voltametria cíclica realizados em $0,5 \mathrm{~mol} \mathrm{~L}^{-1}$ de $\mathrm{KOH}$, onde somente o eletrocatalisador casca-núcleo exibiu o perfil característico do Pd.
\end{abstract}

\section{INTRODUÇÃO}

A célula de combustível de álcool direto (DAFC) é um dispositivo promissor como fonte de energia altamente eficiente para a geração de energia elétrica relativamente limpa (Lamy et al., 2004). O etanol é um combustível promissor em tais células a combustível, e tem atraído recentemente um interesse na pesquisa. Devido à sua elevada densidade de energia e o fato de ser uma fonte renovável de energia, que pode ser produzido em grande escala a partir da biomassa. O etanol é também considerado como "uma fonte de energia limpa", uma vez que é menos tóxico do que o metanol. Células a combustível de etanol Direto (DEFCs) podem ser ácidas ou alcalinas com base no eletrólito. 
Com a intensa investigação no desenvolvimento de membranas de troca protônica a área de reação de oxidação do etanol (ROE), em meio alcalino tem atraído muita atenção e recentes avanços na ciência e tecnologia em nanoescala têm gerado novas ondas em várias áreas. Diversos materiais nanoestruturados têm manifestado as suas grandes potencialidades na compreensão dos processos de oxidação de moléculas orgânicas (Liang et al., 2009).

Estudos pioneiros recentes têm demonstrado que os catalisadores bimetálicos mostram propriedades catalíticas superiores, que não são atingíveis pelos seus homólogos monometálicos, proporcionando perspectivas atraentes para o efetivo desempenho catalítico. Nanoestruturas casca-núcleo representam uma classe muito interessante de catalisadores. Por manipulação das suas composições e/ou características estruturais que apresentam. Desta forma pode-se induzir ao um maior efeito destes catalisadores para a oxidação de álcoois (Peng e Yang, 2009).

Apesar dos avanços impressionantes no design de sistemas de catalisadores casca-núcleo com multi-composições é de se notar que esses materiais nanoestruturados são geralmente preparados por um método de crescimento em várias etapas mediadas por sementes, em que o tamanho e forma da partícula é incontrolável, sem o uso de uma semente uniforme pré-formada (Wang et al., 2010). Nanopartículas de Pd-Au são excelentes catalisadores para uma série de reações incluindo a oxidação de etanol (Ksar et al., 2009). As propriedades catalíticas da junção de $\mathrm{Au}$ e $\mathrm{Pd}$ exibem resultados satisfatórios em eletroquímica. Camadas externas de $\mathrm{Pd}$ depositadas sobre superfícies de monocristais de $\mathrm{Au}$ foram estudadas em detalhe, como um sistema de modelo bem definido (Takahasi et al., 2000).

Neste estudo foi realizada a síntese dos eletrocatalisadores $\mathrm{Pd}$, Au e $\mathrm{Pd}_{1-x}-\mathrm{Au}_{x} / \mathrm{C}\left(\mathrm{Pd}_{0,75}\right.$ $\mathrm{Au}_{0,25} / \mathrm{C}, \mathrm{Pd}_{0,66}-\mathrm{Au}_{0,33} / \mathrm{C}, \mathrm{Pd}_{0,50}-\mathrm{Au}_{0,50} / \mathrm{C}, \mathrm{Pd}_{0,66}-\mathrm{Au}_{0,33} / \mathrm{C}, \mathrm{Pd}_{0,25}-\mathrm{Au}_{0,75} / \mathrm{C}$ e $\left.\mathrm{Pd}_{0,75} @ \mathrm{Au}_{0,25} / \mathrm{C}\right) . \mathrm{O}$ tamanho das partículas foram caracterizadas por microscopia eletrônica de transmissão (MET), Difração de raios X (DRX), e um dos métodos mais modernos de espectroscopia in situ como FTIR foi empregado para identificar os intermediários de superfície. As propriedades eletroquímicas dos suportes foram caracterizadas por técnicas eletroquímicas utilizando um potenciostato/galvanostato.

\section{Metodologia}

\subsection{Seção experimental}

$\mathrm{Na}$ síntese das nanopartículas de $\mathrm{Pd}-\mathrm{Au} / \mathrm{C}$ foram utilizados $\mathrm{AuCl}_{3}$ e $\mathrm{PdCl}_{2}$ (Sigma-Aldrich), como sais metálicos. Inicialmente o catalisador Pd@ $\mathrm{Au} / \mathrm{C}$ foi preparado por deposição de $\mathrm{AuCl}_{3}$ em carbono Black (Alfa Aesar/Acetylene, $99.9 \%$ - A Johnson Matthey Company). O carbono foi adicionado a uma solução de $\mathrm{HCl} 0.4 \mathrm{~mol} \mathrm{~L}{ }^{-1}+\mathrm{AuCl}_{3}$ e a mistura foi ultrasonificada para dispersão do carbono e em seguida levada a agitação durante $1 \mathrm{~h}$. Hidróxido de amônio $\left(\mathrm{NH}_{4} \mathrm{OH}\right.$, Vetec) a $32 \%$ foi então adicionado gota a gota à solução mistura, e esta agitada durante 10 min, a 
fim de atingir o $\mathrm{pH} \approx 10 . \mathrm{O} \mathrm{NaBH}_{4}$, agente redutor dos sais, foi dissolvido em cerca de $10 \mathrm{ml}$ de $\mathrm{H}_{2} \mathrm{O}$ ultrapura (Millipore) e esta foi rapidamente adicionada à mistura. Uma vez que a suspensão teve uma cor amarela clara após a adição de $\mathrm{NaBH}_{4}$, isto resultou em um sobrenadante límpido e a mistura foi submetido a $24 \mathrm{~h}$ de agitação vigorosa. Após esse tempo o catalisador suportado foi centrifugado a $3200 \mathrm{rpm}$ (CENTRIBIO, 80-2BSN). O compósito foi lavado com água, submetido à filtragem a vácuo e seco por evaporação a $25{ }^{\circ} \mathrm{C}$. Então, o pó com nanopartículas de $\mathrm{Au} / \mathrm{C}$ Black foi recuperado.

Supondo-se que neste ponto todos os íons metálicos na solução tinham sido reduzidos por $\mathrm{NaBH}_{4}$ e depositado sobre o carbono, resultando em nanopartículas de Au/C Black. Então, uma solução de $0.4 \mathrm{~mol} \mathrm{~L}{ }^{-1}$ de $\mathrm{HCL}+\mathrm{PdCl}_{2}$ foi preparada e o pó contendo $5 \%$ de ouro foi utilizado como suporte para deposição das partículas de paládio. A solução foi submetida à agitação por mais $24 \mathrm{~h}$ e o pó obtido foi recuperado por centrifugação, lavado com água e seco mais uma vez por evaporação. Os catalisadores $\mathrm{Pd} / \mathrm{C}, \mathrm{Au} / \mathrm{C}$ e $\mathrm{Pd}_{1-x}-\mathrm{Au}_{\mathrm{x}} \mathrm{C}\left(\mathrm{Pd}_{0,75}-\mathrm{Au}_{0,25} / \mathrm{C}, \mathrm{Pd}_{0,66}-\mathrm{Au}_{0,33} / \mathrm{C}\right.$, $\mathrm{Pd}_{0,50}-\mathrm{Au}_{0,50} / \mathrm{C}, \mathrm{Pd}_{0,66}-\mathrm{Au}_{0,33} / \mathrm{C}, \mathrm{Pd}_{0,25}-\mathrm{Au}_{0,75} / \mathrm{C}$ e $\mathrm{Pd}_{0,75} @ \mathrm{Au}_{0,25} / \mathrm{C}$ ) foram sintetizados por um procedimento similar. O carbono foi adicionado a uma solução de $0.4 \mathrm{~mol} \mathrm{~L}-1$ de $\mathrm{HCL}+\mathrm{AuCl}_{3}+$ $\mathrm{PdCl}_{2}$. Os metais foram impregnados no carbono Black com a utilização de $\mathrm{NaBH}_{4}$, resultando em ligas de $\mathrm{PdAu} / \mathrm{C}$.

As medidas eletroquímicas foram realizadas numa célula de vidro Pyrex ${ }^{\circledR}$ de um único compartimento, usando um potenciostato Autolab/Galvanostato, PGSTA Modelo T128N. O eletrodo de trabalho para cada teste foi preparado a partir de uma camada ultrafina de suspensão sobre um eletrodo de carbono vítreo. Para isso, foi utilizada uma suspensão contendo o composto catalítico, $1000 \mu \mathrm{L}$ de álcool isopropílico e $15 \mu \mathrm{L}$ de solução a $0,50 \%$ de Náfion (SigmaAldrich). A mistura resultante foi levada ao banho de ultrassom para se tornar homogênea e, em seguida, uma camada de $10 \mu \mathrm{L}$ foi depositada no eletrodo de carbono vítreo com $10 \mathrm{~mm}$ de diâmetro. Em seguida, seco ao ar ambiente e hidratado por 1 min. Para todos os resultados, uma placa de Pt de $1 \mathrm{~cm}^{2}$ foi utilizada como contra eletrodo. O eletrólito utilizado foi $0,5 \mathrm{~mol} \mathrm{~L}^{-1}$ $\mathrm{KOH}$ (Sigma-Aldrich $99 \%$ ) e as concentrações do álcool utilizadas durante os testes de oxidação foram de $0,5 \mathrm{~mol} \mathrm{~L}^{-1}$ de etanol (Sigma-Aldrich, $96 \%$ ). Os potenciais foram determinados utilizando um eletrodo de hidrogênio na mesma solução (EHMS) isolado por um capilar de Luggin.

A atividade catalítica frente à oxidação de etanol também foi estudada por espectroscopia no infravermelho com transformada de Fourier in situ. Para os experimentos espectroeletroquímicos, os espectros foram coletados nas mesmas condições após saltos sucessivos de potencial desde $50 \mathrm{mV}$ até $1200 \mathrm{mV}$. A radiação passou sequencialmente em uma janela de $\mathrm{CaF}_{2}$ e atingiu uma camada fina (de $2 \mu \mathrm{L})$ da suspensão do catalisador posta sobre um eletrodo de ouro polido e refletida pela superfície do eletrodo. Os padrões de difração dos catalisadores $\mathrm{Pd} @ \mathrm{Au} / \mathrm{C}$ foram obtidos em um difratômetro de raios X (RIGAKU modelo ULTIMA UNIVERSAL + RINT 2000/PC) operando com a radiação $\mathrm{Cu} \mathrm{K}_{\alpha}(\lambda=0,15406 \mathrm{~nm})$ com padrões de difração gerados a $40 \mathrm{KV}$ e $40 \mathrm{~mA}$, com velocidade de $2^{\circ} \mathrm{min}^{-1}$. As fases de composição do catalisador foram obtidas através do programa (Match-phase identification from poder diffration) de acordo com os padrões JCPDS-International Centre For Diffraction Data. E os tamanho e 
morfologia dos eletrocatalisadores foram analisados por um microscópio eletrônico de transmissão (MET).

\section{Resultados e discussões}

Para conhecer a morfologia das nanopartículas e a estrutura da fase dos catalisadores formados após a síntese, foram realizadas microscopias para as amostras (Pd:Au) 50:50, 66:33 e 33:66. Além dos padrões de DRX dos catalisadores Pd, Au, e das amostras modificadas com PdAu. Resultados comparados conforme a Figura 1.
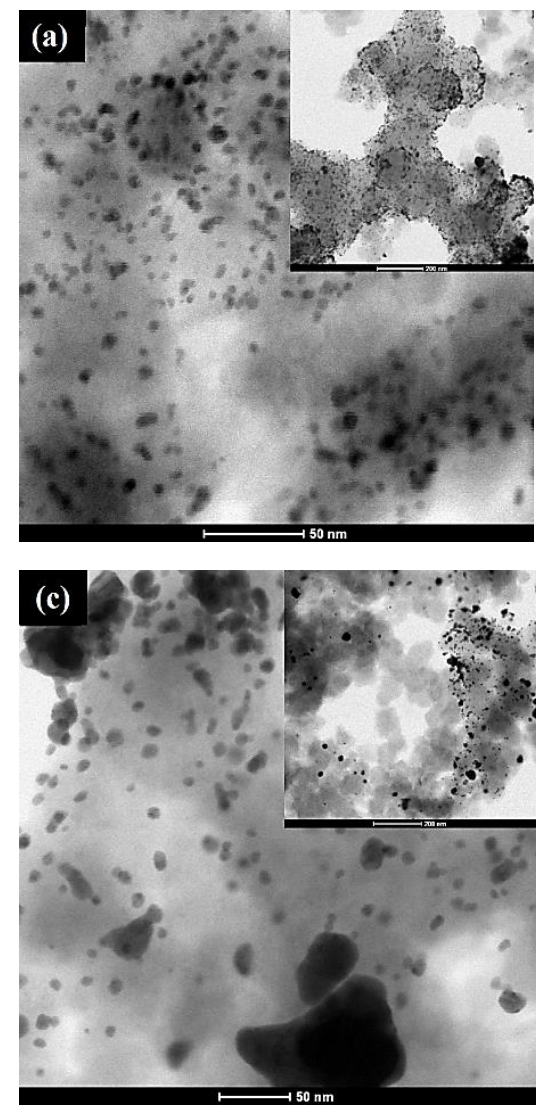
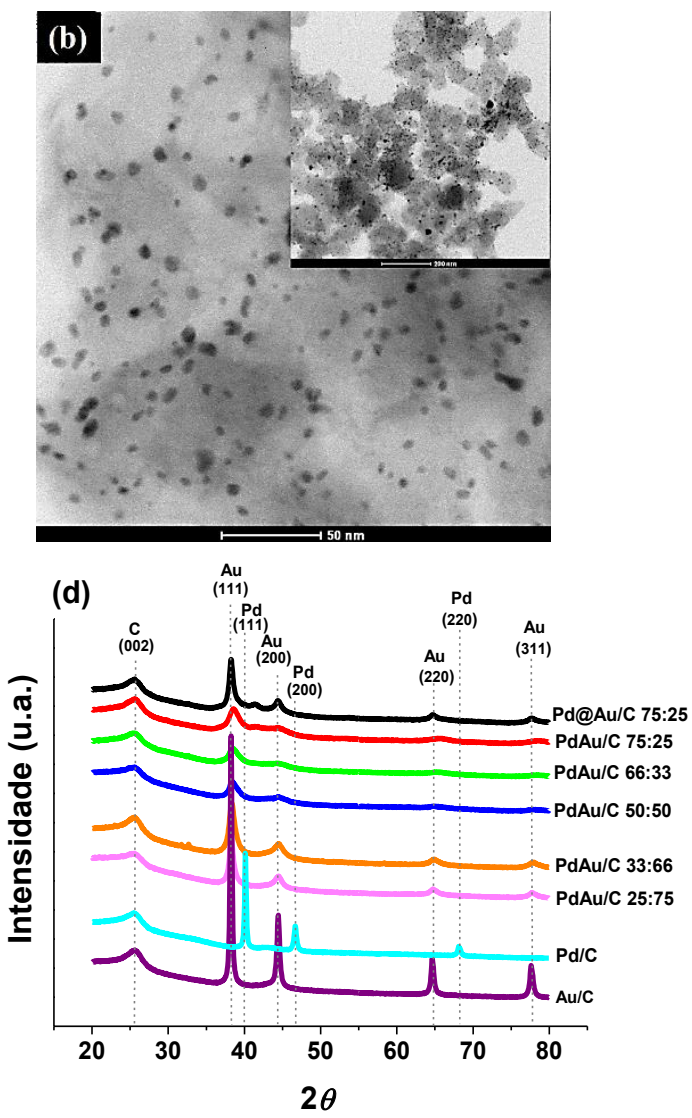

Figura 1. (a), (b) e (c) Imagens de MET dos eletrocatalisadores Pd:Au (50:50), (66:30) e (75:25). (c) Difratogramas de raios $\mathrm{X}$ para os eletrocatalisadores $\mathrm{Pd} / \mathrm{C}, \mathrm{Au} / \mathrm{C}$, para a estrutura casca-núcleo Pd@Au/C (75:25) e ligas PdAu/C (75:25, 66:33, 50:50, 33:66 e 25:75) obtidos com irradiação por feixe de elétrons. As linhas verticais correspondem aos valores dos planos $\mathrm{CFC}$ do $\mathrm{Au} / \mathrm{C}$ e do $\mathrm{Pd} / \mathrm{C}$. 
As imagens de MET paras as composições 50:50 e 66:33 (Figura 1 (a) e Figura 1(b)) indicam um espalhamento uniforme das nanopartículas sobre o suporte de carbono. Na composição 33:66 (Figura 1 (c) observa-se aglomerados no suporte de carbono. As figuras insertas à direita das micrografias representa as mesmas amostras em uma escala de $200 \mathrm{~nm}$.

De acordo coma Figura 1 (d), para todas as amostras, a existência de picos de difração em torno de $2 \theta=26.0^{\circ}$, característico do plano (002) presenta a estrutura hexagonal do carbono (JCPDF $\mathrm{N}^{\circ}$ 00-001-0640) (Duo et al., 2009). Para as amostras de $\mathrm{Pd} / \mathrm{C}$ e $\mathrm{Au} / \mathrm{C}$ são encontradas difrações de uma estrutura cúbica de face centrada (CFC), o que corresponde à estrutura dos metais puros em grandes quantidades (Nie et al., 2007). Para uma leitura realizada de 20 a $80^{\circ}$ em $2 \theta$, o difratograma do $\mathrm{Pd} / \mathrm{C}$ mostrou três picos de difração a cerca de $2 \theta=40.2,46.6$ e $68.1^{\circ}$, que estão associados com os planos (111), (200) e (220) do $\mathrm{Pd}$, respectivamente. O eletrocatalisador $\mathrm{Au} / \mathrm{C}$ apresentou quatro picos de difração em torno de $2 \theta=38.2,44.6,65.1 \mathrm{e}$ $77.8^{\circ}$, atribuídos aos planos (111), (200), (220) e (311) do Au (Zhu et al., 2009). Resultados mostram que os eletrocatalisadores liga $\mathrm{PdAu} / \mathrm{C}$ (25:75) e (33:66) exibem apenas picos característicos de uma estrutura CFC rica em Au. A partir dos difratogramas das amostras $\mathrm{PdAu} / \mathrm{C}$ da Figura 1(d) (50:50), (66:30) e (75:25), torna-se claramente visível deslocamentos de picos para valores positivos (para ângulos maiores que $2 \theta$ ), sugerindo a incorporação de átomos de Pd na rede cristalográfica do Au.

Conforme a Figura 2, as varreduras voltamétricas foram realizadas na faixa de potenciais de $\mathrm{E}_{i}=0.05 \mathrm{~V}$ a $\mathrm{E}_{f}=1.0 \mathrm{~V}$ em relação ao eletrodo de referência de hidrogênio preparado em solução 0,5 mol L${ }^{-1} \mathrm{KOH}$. E em $0,5 \mathrm{~mol} \mathrm{~L}^{-1} \mathrm{KOH}+0,5 \mathrm{~mol} \mathrm{~L}^{-1} \mathrm{CH}_{3} \mathrm{CH}_{2} \mathrm{OH}$ (Figura 2 (b)). $\mathrm{Na}$ Figura 2 (a) e 2(b), estão os perfis diferentes de VC para as nanoestruturas $\mathrm{Pd}_{1-x}-\mathrm{Au}_{x} / \mathrm{C}$. Assim, três regiões podem ser observadas durante a varredura direta para os eletrodos liga com 75 e 50 $\%$ de $\mathrm{Pd}$ em sua composição, as que são atribuídas a diferentes processos eletroquímicos ocorrendo na superfície dos eletrodos à base de Pd. Os picos I e II, compreendidos entre os potenciais $0,1-0,25 \mathrm{~V}$ e $0,25-0,40 \mathrm{~V}$, respectivamente, corresponde aos picos decorrentes à oxidação do hidrogênio adsorvido. O pico III, aproximadamente acima de $0,75 \mathrm{~V}$, é atribuído à formação de óxidos de paládio sobre a superfície dos catalisadores (Liang et al., 2009). Embora o mecanismo do processo de oxidação ainda não esteja claro, tem sido aceito que $\mathrm{OH}^{-}$é formado quimicamente na fase inicial de óxidos, e em seguida, transformado em óxidos de valências superiores a potenciais mais elevados. Os picos durante a varredura catódica, entre 0,6 e 0,9 V, são atribuídos à redução de óxidos de Pd (pico IV) (Zhou et al., 2007).

Na Figura 2 (c) a densidade de corrente de pico do catalisador $\mathrm{Pd} / \mathrm{C}$ foi $j=631 \mathrm{~A} \mathrm{~g}_{\mathrm{Pd}}{ }^{-}$ ${ }^{1} . \mathrm{cm}^{-2} \mathrm{o}$ da área geométrica do eletrodo), inferior aos catalisadores $\mathrm{PdAu} / \mathrm{C}$ (66:33), $\mathrm{PdAu} / \mathrm{C}$ (50:50) e $\mathrm{PdAu} / \mathrm{C}$ (33:66), apresentando densidades de corrente de pico de 1556, 841 e $2271 \mathrm{~A}$ $\mathrm{g}_{\mathrm{Pd}}{ }^{-1} . \mathrm{cm}^{-2}$, respectivamente. $\mathrm{O}$ catalisador $\mathrm{PdAu} / \mathrm{C}(66: 33)$ mostrou-se atividade superior durante a oxidação do etanol, com maior densidade de corrente de pico anódico e menor potencial de início de oxidação (0.47 V vs. EHMS), em comparação com outros eletrocatalisadores binários na região de interesse de uma célula a combustível $(0,50$ a 0,60 V) diretamente alimentada com etanol. 

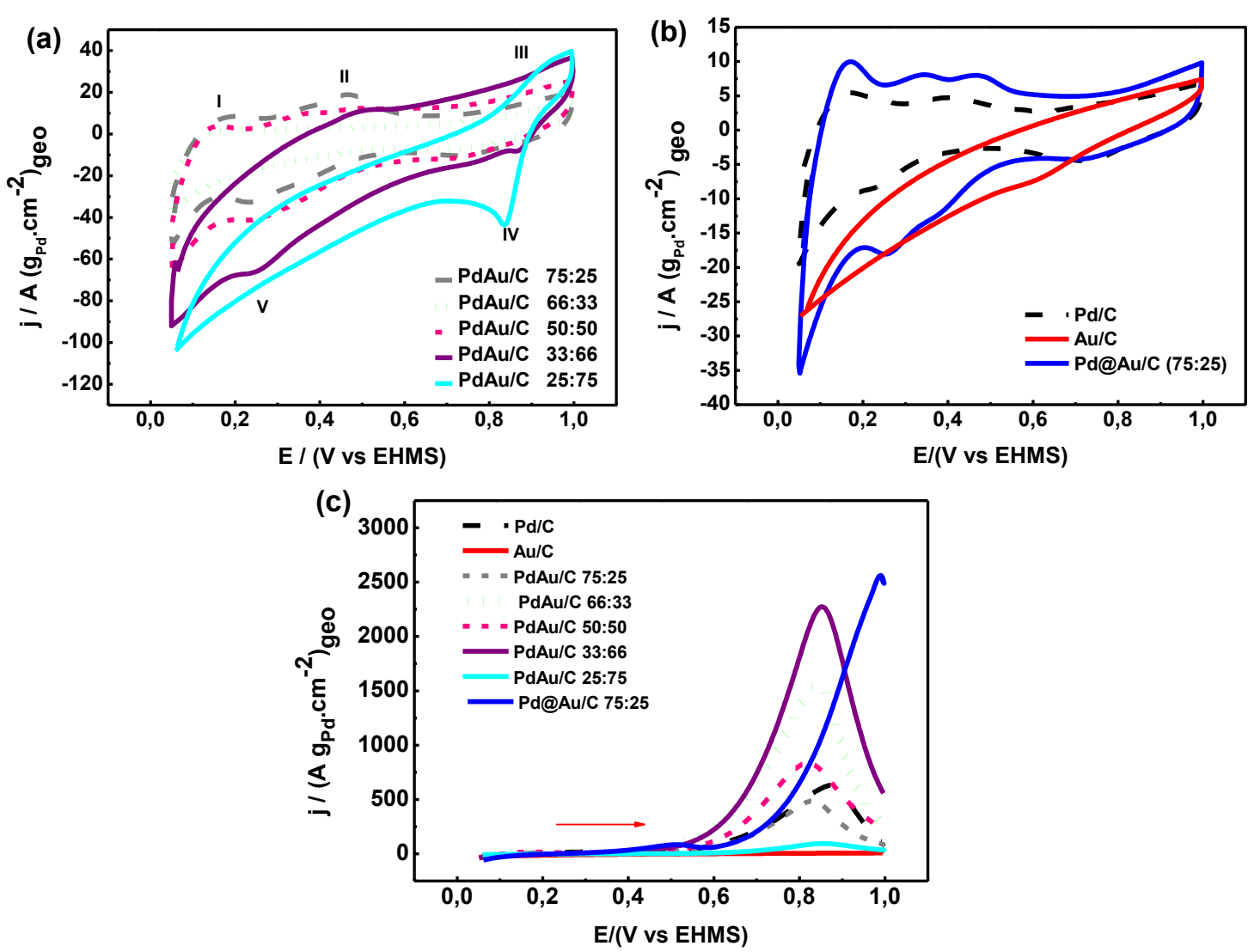

Figura 2. (a) Voltamogramas cíclicos dos catalisadores e ligas $\mathrm{Pd}_{1-x}-\mathrm{Au}_{x} / \mathrm{C}$ (75:25, 66:33, 50:50, 33:66 e 25:75) e (b) Voltamogramas cíclicos dos catalisadores Pd@ $\mathrm{Au} / \mathrm{C}$ (75:25), $\mathrm{Pd} / \mathrm{C}$ e $\mathrm{Au} / \mathrm{C}$ em $0,5 \mathrm{~mol} \mathrm{~L}^{-1} \mathrm{H}_{2} \mathrm{SO}_{4}$. (c) Oxidação de etanol sobre os eletrocatalisadores $\mathrm{Pd}, \mathrm{Au}$ e $\mathrm{Pd}_{1-x^{-}}$ $\mathrm{Au}_{\mathrm{x}} \mathrm{C}$ em $0,5 \mathrm{~mol} \mathrm{~L}^{-1} \mathrm{H}_{2} \mathrm{SO}_{4}+0,5 \mathrm{~mol} \mathrm{~L}^{-1} \mathrm{CH}_{3} \mathrm{CH}_{2} \mathrm{OH}, v=20 \mathrm{mV} \mathrm{s}^{-1}$.

A maior atividade catalítica deste catalisador pode ser atribuída ao mecanismo bifuncional onde espécies de Pd estão disponíveis para adsorção de etanol e Au fornece espécies oxigenadas para a oxidação de intermediários adsorvidos (Bianchini e Shen, 2009). É provável que a atividade catalítica mais elevada durante a oxidação do etanol para o eletrodo Pd@ Au/C corresponda ao recobrimento de átomos de $\mathrm{Au}$ por nanopartículas de $\mathrm{Pd}$, já que resultados por HAADF-STEM comprovam a estrutura casca-núcleo deste catalisador. Este comportamento pode ser devido à doação de elétrons a partir do orbital- $d$ do Au, ou melhor, devido às distâncias interatômicas de Pd-Pd e/ou Au-Au (Roudgar e Grob, 2003).

A Figura 3 mostra os espectros de FTIR in situ da oxidação de etanol sobre o eletrocatalisador casca-núcleo $(\mathrm{Pd} @ \mathrm{Au} / \mathrm{C})$ e a liga de $\mathrm{PdAu} / \mathrm{C}$ nas mesmas composições. Os resultados foram obtidos em potenciais que variam entre 400 a $1000 \mathrm{mV}$ com um intervalo de $100 \mathrm{mV}$. As três bandas de IR para baixo em 1551, 1413 e $1345 \mathrm{~cm}^{-1}$ são atribuídas aos íons acetato $\left(\mathrm{CH}_{3} \mathrm{COOH}^{-}\right)$aparecem quando $\mathrm{E}>600 \mathrm{mV}$, para ambos os catalisadores. Observa-se uma banda em $2343 \mathrm{~cm}^{-1}$, correspondente do $\mathrm{CO}_{2}$ (existente como $\mathrm{CO}_{3}{ }^{2-}$ em meio alcalino) resultado da oxidação completa de etanol (Zhou et al., 2010). 

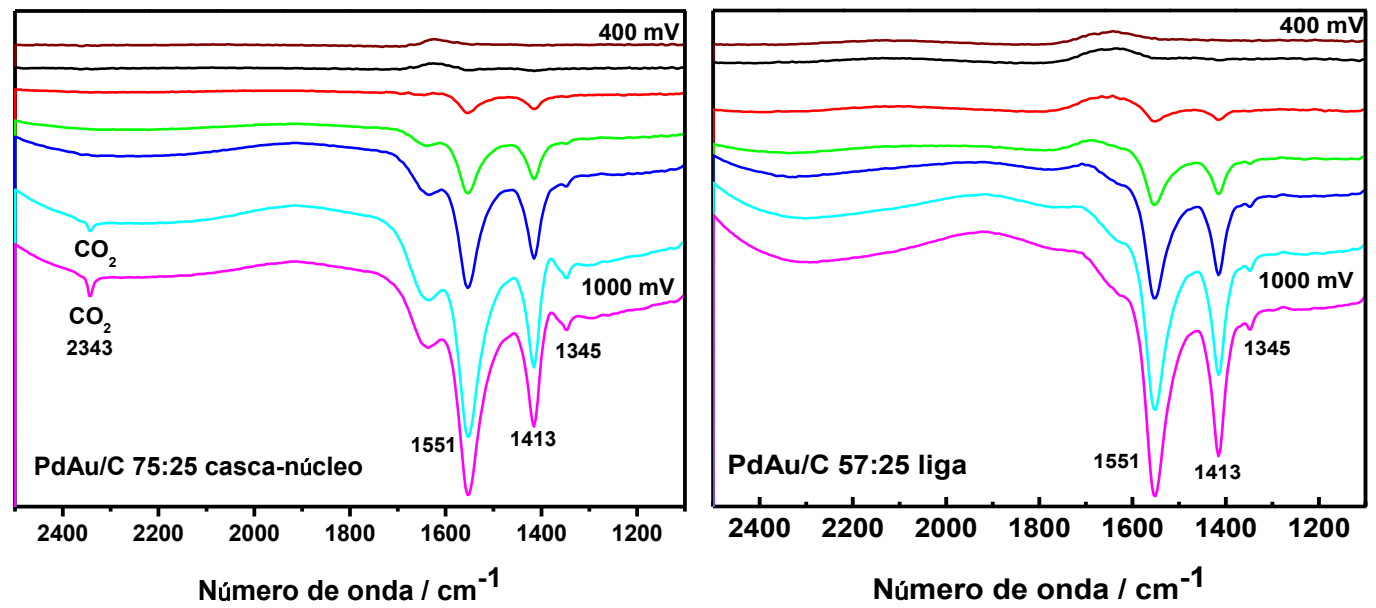

Figura 3. FTIRs de 400 a 1000 mV Pd@Au/C (75:25), PdAu/C (75:25) em solução de KOH 0,5 $\mathrm{mol} \mathrm{L}+1+\mathrm{CH}_{3} \mathrm{CH}_{2} \mathrm{OH} 0,5 \mathrm{~mol} \mathrm{~L}$.

De acordo com Zhou et al. (2010), o aparecimento de $\mathrm{CO}_{2}$ sugere que a maior parte das moléculas da base $(\mathrm{KOH})$ em solução foram neutralizadas devido à oxidação do etanol. A banda de $\mathrm{CO}_{2}$ para o catalisador casca-núcleo $\left(\mathrm{Pd}_{0,75} @ \mathrm{Au}_{0,25} / \mathrm{C}\right)$ foi $77,8 \%$ superior ao catalisador liga $\mathrm{Pd}_{0,75} \mathrm{Au}_{0,25} / \mathrm{C}$. A partir da integração da banda 1413 e $1551 \mathrm{~cm}^{-1}$ de acetato em um potencial de $900 \mathrm{mV}$ onde ocorre o pico de oxidação do álcool por voltametria os valores encontrados para o catalisador liga $\mathrm{PdAu}$ foram $616,37 \mathrm{~cm}^{-1}$ e $279,34 \mathrm{~cm}^{-1}$ comparados ao $\mathrm{PdAu}$ casca-núcleo 445,23 e $176,97 \mathrm{~cm}^{-1}$,respectivamente. Isso indica que para o eletrocatalisador liga o produto principal é o acetato, resultando numa oxidação incompleta.

\section{CONCLUSÃO}

Neste trabalho, a oxidação do etanol sobre eletrodos de PdAu em solução de 0,5 mol $\mathrm{L}^{-1} \mathrm{KOH}$ foi estudada por meio de voltametria cíclica e espectroscopia FTIR in situ. Os testes de voltametria indicam que a oxidação do etanol ocorre em $0,85 \mathrm{~V}(\mathrm{Pd}: \mathrm{Au})$ e $0,90 \mathrm{~V}$ (Pd@Au), na varredura de potencial positivo, e que para a estrutura Pd@Au/C (75:25) em 0,9 $\mathrm{V}$ ocorre à oxidação a $\mathrm{CO}_{2}$, o que não foi observado para liga, com maiores intensidades de bandas de acetato nos espectros de FTIR. Nos resultados de FTIR in situ, durante a oxidação de etanol evidencia-se uma alta quantidade de produção de $\mathrm{CO}_{2}$ para o catalisador $\mathrm{Pd} @ \mathrm{Au} / \mathrm{C}$ (75:25) comparado ao catalisador liga que apresentou na integração da banda $2343 \mathrm{~cm}^{-1}$ uma área de $1.738 \mathrm{~cm}^{-1}$. Isso mostra que essa maior reatividade para o catalisador Pd@ $\mathrm{Au} / \mathrm{C}$ pode ser atribuída a facilidade da quebra da ligação $\mathrm{C}-\mathrm{C}$. Além disso foi observada uma menor quantidade de ácido acético a potenciais de $0,9 \mathrm{~V}$ para a nanoestrutura Pd@Au/C. O presente estudo indica que eletrocatalisadores de Pd puro e Au puro apresentam baixa eficiência para a oxidação do etanol em soluções alcalinas, e uma maior exploração de catalisadores de cascanúcleo à base de $\mathrm{PdAu}$ mostra-se eficiente para quebrar ligação $\mathrm{C}-\mathrm{C}$ sendo importante para as células a combustível alcalinas de etanol direto. 


\section{REFERÊNCIAS}

BIANCHINI, C.; SHEN, P. K., Palladium-based electrocatalysts for alcohol oxidation in half cells and in direct alcohol fuel cells, Chem. Rev., v. 109, p. 4183-4206, 2009.

DU CY; CHEN M; CAO XY; YIN GP. SHI PF. A novel CNT@ $\mathrm{SnO}_{2}$ core-sheath nanocomposite as a stabilizing support for catalysts of proton exchange membrane fuel cells. Electrochem. Commun., v. 11, p. 496-498, 2009.

LAMY, C.; ROUSSEAU, S.; BELGSIR, E. M.; COUTANCEAU, C.; LÉGER, J.-M. Recent progress in the direct ethanol fuel cell: development of new platinum-tin electrocatalysts, Z.X. LIANG, T.S; ZHAO, J.B.; XU. L.D. ZHU, Mechanism study of the ethanol oxidation reaction on palladium in alkaline media, Electrochim. Acta, v. 54, p. 2003-2208, 2009.

LIANG ZX.; ZHAO TS. XU JB. Mechanism study of the ethanol oxidation reaction on palladium in alkaline media. Electrochim. Acta, v. 54, p. 2203-2208, 2009.

KSAR, F. A.; RAMOS, L.; KEITA, B.; NADJO, L.; BEAUNIER, P.; REMITA, H.; Bimetallic Palladium-Gold Nanostructures: Application in Ethanol Oxidation, Chem. Mater., v. 21, p. 3677-3677, 2009.

NIE M.; SHEN PK. WEI ZD. Nanocrystalline tungsten carbide supported Au-Pd electrocatalyst for oxygen reduction. J. Power Sources, v. 167, p. 69-73, 2007.

PENG, Z. YANG, H. Designer platinum nanoparticles: Control of shape, composition in alloy, nanostructure and electrocatalytic property, Nano Today, v. 4, p. 143-164, 2009.

ROUDGAR A. and A. GROß, Local reactivity of thin Pd overlayers on Au single crystals, $J$. Electroanal. Chem., v. 548, p. 121-130, 2003.

TAKAHASI, M.; Y.HAYASHI; J. MIZUKI, K.; TAMURA; T. KONDO; H. NAOHARA and K. UOSAKI, "Pseudomorphic Growth of Pd Monolayer on Au(111) Electrode Surface", Surf. Sci., v. 461, p. 213-218, 2000.

WANG, D.; XIN,H. L.; YU,Y.; WANG, H.; RUS, E.; MULLER, D. A. ABRUÑA, H.D.; PtDecorated PdCo@Pd/C Core-Shell Nanoparticles with Enhanced Stability and Electrocatalytic Activity for the Oxygen Reduction Reaction, J. Am. Chem. Soc., v. 132, p. 17664-17666, 2010.

ZHOU WJ, LEE JY. Highly active core-shell Au@Pd catalyst for formic acid electrooxidation. Electrochem. Commun., v. 9, p. 1725-1729, 2007.

ZHOU, Z.-Y.; WANG, Q.; LIN, J-L., TIAN, N. SUN, S.-G., In situ FTIR spectroscopic studies of electrooxidation of ethanol on Pd electrode in alkaline media, Electrochim. Acta, v. 55, p. 7995-7999, 2010.

ZHU LD.; ZHAO TS.; XU JB. LIANG ZX. Preparation and characterization of carbon supported submonolayer palladium decorated gold nanoparticles for the electrooxidation of ethanol in alkaline media. J. Power Sources, v. 187, p. 80-84, 2009. 